\title{
NECESSIDADES DE FORMACCÃO DOS TREINADORES PARA O VOLEIBOL ATUAL
}

\section{Training needs of coaches volleyball for the current}

\author{
Flávio Márcio Marinho' ${ }^{1}$, Alexandre Silva de Oliveira2,; Bruno Pena Couto3; \\ Nádia Fernanda Schmitt Marinho4; Carlos Alberto Serrão dos Santos Januário ${ }^{5}$ \\ ${ }^{1}$ Mestre. Colégio Militar, Belo Horizonte, MG. \\ ${ }^{2}$ Especialista. Colégio Santo Agostinho, Belo Horizonte, MG. \\ ${ }^{3}$ Doutor. Universidade Federal de Minas Gerais, Belo Horizonte, MG. \\ ${ }^{4}$ Mestre. Universidade Salgado de Oliveira, Belo Horizonte, MG. \\ ${ }^{5}$ Doutor. Faculdade de Motricidade Humana, Lisboa, PT.
}

\begin{abstract}
Resumo: O presente estudo teve como objetivos identificar as necessidades de formação percebidas pelos treinadores de voleibol, em relação as áreas de formação e suas competências, alem identificar as ações de formação que os treinadores de voleibol vêm buscando para seu desenvolvimento profissional.

A amostra foi composta por 38 treinadores de voleibol, sendo 7 das categorias de base das seleções brasileiras e de 31 treinadores que atuam nas regiões Sudeste e Sul do país. A coleta de dados ocorreu em duas fases: a primeira através de questionário sobre as necessidades de formação e a segunda através de entrevista de aprofundamento. Como resultados indentificamos que todas as áreas de formação são consideradas necessárias ou muito necessárias e as competências de Conhecimento do Conteúdo estão relacionadas a rápida evolução do Voleibol.

Palavras-chave: Educação Física. Voleibol. Treinadores. Necessidades de Formação.
\end{abstract}

Abstract: This study aimed to identify the needs perceived by volleyball coaches for the areas of training and skills, besides identifying the actions that the training of volleyball coaches have been searching for their professional development. The sample consisted of 38 volleyball coaches, and 7 of the basic categories of Brazilian teams and 31 coaches who work in Southeast and South. Data collection occurred in two phases: the first through the questionnaire on training needs and the second through-depth interview. As a result we identified all areas of training are considered necessary or very necessary, skills and knowledge of the contents are related to rapid development of Volleyball.

Keywords: Physical Education. Volleyball. Coaches. Training Needs.

Aceito em 19/02/13 - Revista de Educação Física 2013 Abr; 157:38-46. Rio de Janeiro - Brasil

\section{INTRODUÇÃO}

O voleibol se apresenta com complexas variações táticas, exigindo de seus praticantes capacidades físicas, habilidades motoras e cognitivas. Nesse sentido, foi criada uma variedade de sistemas táticos ao longo dos anos, o que modificou o jogo, tornando o voleibol um esporte mais competitivo e dinâmico. Segundo Durrwachter (1984) $)^{(1)}$, o jogo de voleibol apresenta volumosas exigências táticas e técnicas, verificadas por rápidas trocas de situação de jogo.

Essa modificação do voleibol repercutiu em novas necessidades na formação dos treinadores em relação às mudanças e inovações nos campos técnico, tático, físico e psicológico. Isso nos remete a
Marcelo (1992)(2), que diz que um bom domínio do conhecimento didático do conteúdo pode facilitar a aprendizagem através de explicações, demonstrações e planejamento do conteúdo. Fatores estes que são observados em conjunto ao conhecimento sobre os alunos/ atletas e o contexto a que estão inseridos. Buchmann (s/d, cit. in Marcelo, 1992)(2) relata que devemos ter um conhecimento do conteudo com a profundidade que nos permita conseguir organizá-lo mentalmente, a ponto de poder ensiná-lo.

Essas necessidades são individuais e/ou coletivas, o que permite dirigir a formação dos treinadores face às novas demandas da prática profissional. Segundo Ramalho e Nuñez (2001)(3), uma formação sem direção e sem conhecimento das 
suas necessidades reais não se ajusta às mudanças, que exigem cada vez mais uma ação criadora na sua preparação, de acordo com a perspectiva do desenvolvimento da profissionalidade. As necessidades têm sua origem na prática do profissional, neste caso, o treinador, o que, como categoria norteadora, remete à necessidade de pesquisar seu cotidiano profissional e pessoal.

A análise de necessidades de formação, como área de pesquisa, teve o seu aparecimento no final dos anos 60. Na área educativa este tipo de análise vem sendo utilizada como um instrumento fundamental no planejamento e tomada de decisão, obedecendo a uma preocupação de racionalização dos processos formativos e os desejos de conseguir planos mais estruturados e eficazes, que respondam adequadamente às exigências sociais, na intenção de encontrar processos mais eficientes na formação do professor (Rodrigues e Esteves, $1993^{(4)}$.

A realização de pesquisas que proporcionem elementos para uma identificação do comportamento real, do comportamento desejado e das necessidades reais é relevante na renovação da graduação em Educação Física e nos cursos de treinadores. Não foram encontradas pesquisas sobre as necessidades de formação dos treinadores de voleibol. Diante disso, o objetivo do presente estudo foi identificar as necessidades de formação percebidas pelos treinadores de voleibol e suas respectivas ações de formação para desenvolvimento profissional.

\section{METODOLOGIA}

A determinação das necessidades constitui uma pesquisa orientada para identificar junto aos treinadores as competências, as habilidades reais e as desejadas, com o intuito de se construir modelos de desenvolvimento profissional e de melhorar a prestação esportiva. A determinação de necessidades é um momento de grande relevância na hora de organizar planos de formação, pois toma como base a caracterização das possibilidades dos treinadores e seus saberes, tendo como ponto de partida uma reflexão sobre a prática e a definição de metas. As necessidades formativas dos treinadores se constituem num campo necessário e ainda pouco explorado nos processos de sua formação inicial e continuada.

Os modelos e abordagens de análise de necessidades de formação abrangem uma diversidade de técnicas e instrumentos, não havendo técnicas específicas para a sua análise (Kaufman, 1973) $)^{(5)}$, já que as opções dependem dos objetivos pretendidos e dos meios que se dispõe. Para Barbier e Lesne $(1977)^{(6)}$, os processos, as técnicas e os instrumentos a utilizar na análise de necessidades de formação não podem se basear, unicamente, em critérios de natureza técnica.

A técnica de análise de necessidades de formação mais utilizada tem sido o questionário (Silva, $2000)^{(7)}$, por abranger, em pouco tempo, um número considerável de pessoas e o tratamento dos dados recolhidos não oferecer grandes dificuldades, ainda que o mesmo não permita o controle das condições em que as respostas são dadas. Os questionários seguem ao encontro do modelo ou perspectivas que se direcionam para uma concepção de necessidades de formação como discrepância (Kaufman, 1973(5); Stuflebeam ${ }^{(8)}$, 1985; Suarez ${ }^{(9)}$, 1985).

Sobre a amostra, participaram do estudo 38 treinadores, distribuídos em dois grupos:

a) 31 treinadores de Voleibol competitivo, atuando em clubes ou escolas, da região sul e sudeste do Brasil (14 com especialização em treinamento, 14 com graduação em Educação Física, 2 com mestrado e 1 com doutorado);

b) 7 treinadores das comissões técnicas das categorias de base infanto-juvenil e juvenil da seleção brasileira de voleibol (3 com especialização em treinamento, 1 com graduação em Educação Física e 3 com mestrado; um dos entrevistados não completou a graduação em Educação Física, mas é graduado em Administração e possui mestrado na área de Finanças).

$\mathrm{O}$ estudo apresentou duas fases. Na primeira utilizou-se o questionário, adaptado de Ferro (2005) ${ }^{(10)}$, por estar de acordo com a característica exploratória da pesquisa e por facilitar a coleta e a análise dos dados, abrangendo toda a amostra. Neste questionário os voluntários responderam a perguntas sobre áreas de formação profissional, dentro do conteúdo Voleibol e as Funções/Competências 
do treinador seguindo a seguinte escala: Para as áreas de formação profissional dentro do conteúdo voleibol assinalaram como área - (1) Não necessária, (2) Pouco necessária, (3) Necessária, (4) Muito necessária. Para as Funções/Competências do treinador assinalaram como - (1) Necessidade não sentida, (2) Necessidade pouco sentida, (3) Necessidade sentida, (4) Necessidade muito sentida. Lembrando que as 47 funções foram codificadas de F1 a F47 para facilitar o entendimento.

$\mathrm{Na}$ segunda fase realizou-se a entrevista de aprofundamento aos treinadores das categorias de base da seleção brasileira de voleibol, por julgar que estes têm melhores condições de opnar sobre o voleibol nacional, já que para montar as seleções nacionais devem garimpar atletas em várias regiões do país conhecendo as várias possibilidades e necessidades do voleibol nacional. As questões foram tratadas por análise de conteúdo pela técnica de análise temática, buscando aprofundar o universo das necessidades de formação, tornando possível uma análise crítica e compreensiva. O guião foi elaborado a partir do questionário, com o objetivo de elucidar questões menos claras sobre as necessidades dos treinadores e aprofundar aspectos mais complexos no contexto em que atuam, fundamentadas nos objetivos do estudo e na revisão de literatura. Para Triviños (1987)(11), a coleta de dados por meio desse tipo de entrevista, parte de certos questionamentos básicos, fundamentados em teorias, que interessam à pesquisa e que possibilitam um amplo campo de interrogativas.

\section{ANÁLISE ESTATÍSTICA}

Utilizou-se a estatística descritiva básica para descrever e analisar a distribuição de freqüência das variáveis. Para verificar-se a relação existente entre as variáveis de estudo em questão, foi utilizado o teste de qui-quadrado, o qual verifica a dependência ou associação entre as variáveis categóricas. Os testes foram realizados ao nível de $5 \%$ de significância.

\section{RESULTADOS}

Os resultados do questionário foram apresentados em frequência, apontando dados que foram confrontados entre si e, posteriormente, com a aná- lise das entrevistas.

A tabela 1 apresenta a frequência de ações de formação na área técnica de voleibol. De acordo com a análise dos questionários, $98 \%$ das respostas mostrou que os treinadores tiveram, no mínimo, uma ação de formação nos últimos três anos na área técnica de Voleibol.

TABELA 1: MODALIDADES DE AÇÕES DE FORMAÇÃO NA ÁREA TÉCNICA DE VOLEIBOL

\begin{tabular}{l|c|c}
\hline Ações de Formação & N & $\%$ \\
\hline Palestras & 26 & $27 \%$ \\
Seminários & 22 & $23 \%$ \\
Atualização & 15 & $15 \%$ \\
Especialização & 10 & $10 \%$ \\
Oficinas & 9 & $9 \%$ \\
Aperfeiçoamento & 9 & $9 \%$ \\
Outras & 6 & $6 \%$ \\
& & \\
\hline Total & 97 & $100 \%$ \\
\hline
\end{tabular}

Em relação aos entrevistados, mais de $85 \%$ deles acreditam que apenas a formação inicial não é um pré-requisito para uma boa atuação como treinador de voleibol. É possível perceber que a maioria dos treinadores buscou ações complementares, a fim de obterem uma melhora em sua atuação. $\mathrm{Na}$ tabela 2 são apresentadas as modalidades que segundo os resultados dos questionários apresentaram maior aquisição de conhecimento.

TABELA 2: MODALIDADES QUE FORNECERAM MAIOR AQUISIÇÃO DE CONHECIMENTO E DE COMPETÊNCIAS

\begin{tabular}{lcc}
\hline Ações de Formação & N & \% \\
\hline Palestras & 6 & $19 \%$ \\
Seminários & 6 & $19 \%$ \\
Atualização & 6 & $19 \%$ \\
Especialização & 5 & $16 \%$ \\
Aperfeiçoamento & 5 & $16 \%$ \\
Indiferente & 3 & $10 \%$ \\
\hline Total & 31 & $100 \%$ \\
\hline
\end{tabular}

Dentre as ações complementares, foi possível destacar as de menor duração como palestras, seminários e atualizações, além de acompanhamentos e estágios com profissionais experientes ou de renome na área do Voleibol.

A tabela 3 apresenta as modalidades de formação na área de treinamento não diretamente ligadas ao voleibol. 
TABELA 3: MODALIDADES DE AÇÕES DE FORMAÇÃO NA ÁREA DE TREINAMENTO

\begin{tabular}{lcc}
\hline Ações de Formação & N & $\%$ \\
\hline Palestras & 20 & $30 \%$ \\
Oficinas & 10 & $15 \%$ \\
Seminários & 15 & $22 \%$ \\
Atualização & 8 & $12 \%$ \\
Aperfeiçoamento & 5 & $7 \%$ \\
Especialização & 6 & $9 \%$ \\
Mestrado & 2 & $3 \%$ \\
Outra & 1 & $1 \%$ \\
\hline Total & 67 & $100 \%$ \\
\hline
\end{tabular}

Foi possível perceber que a maioria dos treinadores buscou uma formação fora da especificidade do Voleibol tais como, psicologia do esporte, nutrição, treinamento desportivo e fisiologia do esporte, a fim de complementar e ampliar sua intervenção, principalmente na iniciação e com jovens.

Cruzamento das áreas de formação profissional dentro do conteúdo voleibol e funções do treinador/competências profissionais

Com relação às Áreas de Formação Profissional e às Funções/Competências dos treinadores de voleibol observamos através da estatística do qui-quadrado, que algumas competências necessárias ao treinador de Voleibol estão diretamente associadas a áreas de formação. Para facilitar o entendimento essas Funções/Competências foram nomeadas de F1 a F47. Abaixo se encontram os resultados dessas variáveis tomadas como dependentes.

Para a relação entre a função profissional de Identificar elementos críticos das habilidades motoras e combinar progressões pedagógicas que promovam aprendizagens (F1) e o Conhecimento de Conteúdo se apresentou da seguinte maneira: para aqueles que perceberam essa área como "não necessária", observou-se uma concentração de F1 como "não sentida". Para aqueles que perceberam a área como "pouco necessária" ou "necessária" observou-se uma concentração maior de F1 como necessidade sentida; já os que perceberam a área como "muito necessária" sentiram F1 como uma "necessidade sentida" ou "muito sentida".

A relação entre a área de Conhecimento do Conteúdo com a competência Compreender e integrar os aspectos biológicos, psíquico, sociológico e de experiências, no desenvolvimento das habilidades motoras no Voleibol (F6) apresentou-se da seguinte forma: todos os que perceberam a área como "não necessária" também perceberam a competência F6 como "não sentida"; os que perceberam a área como "pouco necessária" tiveram uma maior concentração da competência F6 como uma necessidade "pouco sentida"; aqueles que perceberam a área de Conhecimento do Conteúdo como "necessária"/"muito necessária" consideraram a competência F6 como "sentida".

A área Comunicação apresentou dependência com a Competência de descrever e implementar estratégias para aumentar a interação de comunicação entre os alunos/atletas (F18). As percepções da área de Comunicação tidas como "pouco necessária", "necessária" ou "muito necessária" se relacionaram com F18, apresentando maior concentração como necessidade "sentida" ou muito sentida".

Observou-se que quando a área de Planejamento e Instrução é vista como "necessária" ou "muito necessária", há uma concentração maior em F20 (Planejamento a curto e longo prazo) como necessidade "sentida" ou "muito sentida". Vale ressaltar que, mesmo aqueles que têm o Planejamento e Instrução como área "pouco necessária" consideraram F20 como necessidade sentida.

Vimos também que, $87 \%$ daqueles que consideraram o Planejamento e Instrução como "necessário", perceberam F21 (Utilização de estratégias de instrução) como necessidade "pouco sentida" ou "sentida". E $72 \%$ daqueles que consideraram o Planejamento e Instrução como "muito necessário" perceberam F21 como necessidade "pouco sentida" ou "sentida".

$\mathrm{Na}$ área de Planejamento e Instrução, tida como área "necessária", viu-se uma concentração em relação a F26 (Utilização de demonstração e instrução que liguem conceitos e efeitos da atividade física, em experiências de aprendizagem adequadas ao Voleibol), como necessidade "sentida" e "pouco sentida". No entanto para "muito necessária" ocorre uma maior concentração em necessidade "sentida" e "muito sentida".

Ainda na área de Planejamento e Instrução, vimos uma maior concentração daqueles que a viram como necessária em F27 (Utilização de um 
repertório diversificado de instruções pertinentes, diretas e indiretas, que promovam a aprendizagem do Voleibol) como necessidade "sentida" e "muito sentida". Já para aqueles que a perceberam como "muito necessária" também há uma maior concentração em F27, como necessidade "sentida" ou "muito sentida".

Em relação à área Avaliação dos Alunos e a competência profissional F30 (Interpretar e usar dados da aprendizagem e desempenho, na tomada de decisões durante as aulas, treinos, jogos e planejamento futuro), foi possível observar que aqueles que perceberam a área como "pouco necessária" têm maior concentração da necessidade de F30 em "não sentida" ou "pouco sentida". Já os que consideraram a área como "necessária" ou "muito necessária" houve maior concentração de F30, em necessidade "muito sentida" ou "sentida".

Foi encontrada uma relação entre Reflexão e a competência F31 (Refletir sobre as concepções de ensino do voleibol, justificar e analisar os resultados, metas de ensino e implementação de inovações). Os treinadores que consideraram a Reflexão como "pouco necessária", a concentração de F31 foi maior em necessidade "pouco sentida", mas também existiu uma menor concentração em necessidade "muito sentida". Quando a Reflexão é tida como necessária, F31 apresentou uma concentração maior em necessidade "sentida", seguida de necessidade "pouco sentida". Já a coluna em que a área Reflexão foi considerada "muito necessária" F31 concentra-se em "necessidade sentida" e "muito sentida".

A área Tecnologia está relacionada com a competência F34 (Demonstrar conhecimentos atualizados de aplicações informáticas para o treinamento de Voleibol). Para os treinadores que perceberaram a área como "não necessária" apresentaram-se todos considerando tal competência como necessidade "muito sentida". Aqueles que viram essa área como "pouco necessária" não consideraram como necessidade "sentida". Quando a Tecnologia foi vista como uma área "necessária"/"muito necessária", a competência F34 apresentou uma concentração em necessidade "sentida" e "muito sentida" para esses treinadores.

Foi encontrada também uma relação de depen- dência entre a área de formação ligada ao TrabaIho Colaborativo e a competência F38 (Identificar e procurar recursos na comunidade que aumentem as oportunidades de promoção do voleibol). Os treinadores que consideraram o Trabalho Colaborativo "muito necessário" houve uma maior concentração em necessidade "muito sentida". Para aqueles que consideraram a área de Trabalho Colaborativo "pouco necessária", dividem suas concentrações em necessidade "pouco sentida" e "muito sentida". Quando a área foi considerada "necessária", possui uma concentração bem dividida entre necessidade "pouco sentida", "sentida" e "muito sentida".

A partir do conteúdo das entrevistas realizadas aos 7 treinadores das categorias de base das seleções brasileiras de Voleibol, se apresenta os dados mais relevantes. As entrevistas foram divididas em temas, sendo estes categorizados para facilitar sua análise e entendimento.

No quadro 1 observamos a forma de ingresso no voleibol dos entrevistados. Podemos perceber que 5 dos 7 entrevistados foram ex-atletas da modalidade, o que, segundo os resultados dos questionários, é uma facilidade para o acesso a treinadores mais experientes nos estágios e acompanhamentos.

QUADRO 1. INGRESSO NO VOLEIBOL

\begin{tabular}{|l|l|l|l|l|l|l|l|}
\hline Categorias & \multicolumn{6}{|l|}{ Entrevistados } \\
\hline Ex-atletas da modalidade & & E.2 & E.3 & E.4 & & E.6 & E.7 \\
\hline Estudantes de Educação Física & E.1 & & & & E.5 & & \\
\hline
\end{tabular}

No quadro 2 temos as ações de formação complementar procuradas pelos entrevistados, sendo os cursos, acompanhamentos e estágios as mais procuradas.

\section{QUADRO 2. COMPLEMENTAÇÃO DA FORMAÇÃO} ACADÊMICA

\begin{tabular}{|l|l|l|l|l|l|l|}
\hline Categorias & \multicolumn{5}{|l|}{ Entrevistados } \\
\hline Acompanhamentos e Estágios & E.1 & E.2 & E.3 & E.4 & & \\
\hline Cursos & & E.2 & & E.4 & E.5 & E.6 \\
\hline Prática & E.1 & & & & & \\
\hline
\end{tabular}

Para o quadro 3 temos a importância dada a essas ações complementares de formação, com destaque para os acompanhamentos e estágios. 
QUADRO 3. PERCEPÇÃO DA IMPORTÂNCIA DAS AÇÕES COMPLEMENTARES DE FORMAÇÃO

\begin{tabular}{|l|l|l|l|l|l|l|l|}
\hline Categorias & \multicolumn{6}{|l|}{ Entrevistados } \\
\hline Acompanhamentos e Estágios & E.1 & E.2 & E.3 & E.4 & & & E.7 \\
\hline Estudos & & E.2 & E.3 & & & E.6 & \\
\hline Todas as ações & & & & & E.5 & & \\
\hline
\end{tabular}

Assim como no quadro 3, onde a importância dada aos acompanhamentos e estágios foi destacada, no quadro 4 estas ações estão evidenciadas como as mais proveitosas.

\section{QUADRO 4. AÇÕES COMPLEMENTARES DE FORMAÇÃO} DE MAIOR PROVEITO

\begin{tabular}{|l|l|l|l|l|l|l|l|}
\hline Categorias & \multicolumn{6}{|l|}{ Entrevistados } \\
\hline Acompanhamentos e Estágios & & & E.3 & E.4 & E.5 & E.6 & E.7 \\
\hline Cursos & & E.2 & & & & & \\
\hline Autoformação & E.1 & & & & & & \\
\hline
\end{tabular}

A relevância do conhecimento dos conteúdos e dos conceitos aplicados ao voleibol com jovens apresentou em destaque duas categorias que são apresentadas no quadro 5.

QUADRO 5. RELEVÂNCIA DO CONHECIMENTO DOS CONTEÚDOS E DOS CONCEITOS APLICADOS AO VOLEIBOL COM JOVENS

\begin{tabular}{|l|l|l|l|l|l|l|l|l|}
\hline Categorias & \multicolumn{3}{|l|}{ Entrevistados } \\
\hline $\begin{array}{l}\text { Dosagem das cargas de trabalho de acordo } \\
\text { com as faixas etárias }\end{array}$ & E.1 & E.2 & E.3 & E.4 & E.5 & E.6 & E.7 \\
\hline $\begin{array}{l}\text { Conhecimento técnico, tático e físico, além } \\
\text { de um conhecimento psicológico básico }\end{array}$ & E.1 & E.2 & E.3 & E.4 & & & E.7 \\
\hline Distribuir funções & & & & & & E.6 & \\
\hline
\end{tabular}

O planejamento e avaliação foram subdivididos em quatro categorias, não havendo maior destaque para nenhuma delas e sua distribuição está apresentada no quadro 6 .

QUADRO 6. AVALIAÇÃO E PLANEJAMENTO

\begin{tabular}{|l|l|l|l|l|l|l|l|}
\hline Categorias & \multicolumn{6}{|l|}{ Entrevistados } \\
\hline Avaliação física, técnica e tática & E.1 & E.2 & E.3 & E.4 & & E.6 & \\
\hline Periodicidade da avaliação & & E.2 & E.3 & E.4 & E.5 & & E.7 \\
\hline Planejamento periódico & E.1 & E.2 & & & E.5 & E.6 & \\
\hline Planejar de acordo com a faixa etária & & E.2 & E.3 & E.4 & & & E.7 \\
\hline
\end{tabular}

Quanto aos aspecos relevantes para o treinamento com jovens apresentados no quadro 7, subdividiu-se em oito categorias com destaque para conhecimento das habilidades motoras, progressões didático-pedagógicas, clareza nas Instruções, estratégias de motivação como ferramenta para melhorar o desempenho e feedback contínuo que foram citadas por três entrevistados

\section{QUADRO 7. ASPECTOS RELEVANTES PARA O} TREINAMENTO COM JOVENS

\begin{tabular}{|l|l|l|l|l|l|l|l|l|}
\hline Categorias habilidades & E.1 & E.2 & E.3 & & & & \\
\hline $\begin{array}{l}\text { Conhecimento das drevistados } \\
\text { motoras }\end{array}$ & & & & & & \\
\hline $\begin{array}{l}\text { Progressões didático-pedagógicas: do } \\
\text { fácil para o difícil, do simples para o } \\
\text { complexo }\end{array}$ & E.2 & E.3 & & & & \\
\hline Clareza nas Instruções como & E.1 & E.2 & E.3 & & & & \\
\hline $\begin{array}{l}\text { Estratégias de motivação para melhorar } \\
\text { ferramenta } \\
\text { desempenho }\end{array}$ & & & & & & & \\
\hline Feedback contínuo & E.1 & E.2 & E.3 & & & & \\
\hline Conhecimento do grupo & & & & E.4 & E.5 & & \\
\hline Conhecimento científico atualizado & & & & & & E.6 & \\
\hline Temporalidade das intervenções & & & & & & & E.7 \\
\hline
\end{tabular}

\section{DISCUSSÃO DE RESULTADOS}

Para Bompa (2002)(12), a teoria e a metodologia do treinamento são áreas extensas, cabendo ao treinador distinguir dentre as informações disponíveis em cada ciência, as mais pertinentes à organização do seu trabalho, cujos fundamentos são os princípios do treinamento desportivo. Portanto, para acompanhar a evolução do Voleibol, os treinadores buscam formações, além da modalidade específica.

Dentre as áreas de formação profissional e as funções/competências dos treinadores listadas no questionário, percebeu-se que todas são essenciais para o desenvolvimento do treinador. Porém, foram analisadas com maior ênfase aquelas sentidas pelos treinadores como necessárias/muito necessárias, em associação com as categorias apresentadas nas entrevistas, para assim se destacar os pontos importantes que poderão ser reforçados nos cursos de formação inicial e continuada.

$\mathrm{Na}$ sociedade do conhecimento é necessário que o treinador reformule suas concepções e entenda como diz Nóvoa (2002) $)^{(13)}$, que ter domínio de seu conteúdo e habilidade para comunicação com seus alunos não é suficiente, é preciso desenvol- 
ver outras competências em favor da melhoria do ensino/aprendizagem dentro de áreas da formação, que vão desde o conhecimento do conteúdo até ao conhecimento tecnológico e ao trabalho colaborativo. Com relação a essas ideias, os treinadores envolvidos na pesquisa, ao refletirem sobre as questões da inquirição, fizeram emergir dados a respeito de suas ações e de suas necessidades de formação, que servem de subsídios para que se possa apontar uma trilha para o processo de formação do treinador no trato com o Voleibol.

Com base nos resultados encontrados percebeu-se que os treinadores de Voleibol estão buscando ações de formação (seminários, palestras e especializações, entre outros), procurando um conhecimento específico atualizado, proporcionando mudanças conceituais, novas abordagens e propostas para o ensino do Voleibol. As ações de formação buscadas pelos treinadores se caracterizam como de curta duração. Tais ações, geralmente, têm um custo mais baixo, sendo mais acessível para a maioria dos treinadores: considerando uma agenda de jogos intensa, a curta duração favorece a participação dos treinadores. Dentre os treinadores inquiridos, percebeu-se um número baixo de mestres e doutores: estas modalidades de formação ainda não despertam grande interesse.

Segundo Ramalho e Nuñez (2001) ${ }^{(3)}$, de acordo com a perspectiva do desenvolvimento da profissionalidade, que exigem cada vez mais uma ação criadora na sua preparação uma formação sem direção e sem conhecimento das suas necessidades reais não se ajusta às mudanças. Corroborando com estes autores, os resultados encontrados apontaram que as competências do Conhecimento do Conteúdo, área de formação percebida como necessária/muito necessária, relacionam-se com a rápida evolução do Voleibol nos últimos anos, dentro do contexto tático, físico e em suas regras. Por isso, os treinadores têm que passar por constantes atualizações do conteúdo, principalmente os que estão atuando há mais tempo.

Outra área da formação considerada como necessária ou muito necessária é a de Desenvolvimento e Diversidade que se relacionou com identificar, selecionar e implementar atividades adaptadas ao desenvolvimento do atleta, instruções adequa- das à experiência anterior, características pessoais e necessidades específicas de cada atleta dentro do Voleibol e ainda, a utilização de estratégias e recursos adequados a diferentes necessidades que promovam situações de aprendizagem no Voleibol. Percebeu-se também uma preocupação dos treinadores em relação à dosagem das cargas de trabaIho, relacionando-as com a faixa etária dos atletas. Isso nos remete a Marcelo (1992) (2), que diz que o professor deve possuir um domínio do conhecimento didático do conteúdo para facilitar a aprendizagem por intermédio de explicações, demonstrações e formulação do conteúdo. Estes fatores devem ser observados, concomitantemente, ao conhecimento acerca dos alunos e do contexto onde estão inseridos.

A área de Gestão e Motivação também foi identificada como necessária ou muito necessária pelos inquiridos. Utilizar conhecimentos para a motivação individual e de grupo numa interação positiva capaz de incitar compromissos e auto-motivação na aprendizagem do Voleibol é algo que se interage com uma busca por formação permanente e ampliação de conhecimentos.

Segundo Durrwachter (1984)(1), o jogo de voleibol apresenta volumosas exigências táticas e técnicas, verificadas por rápidas trocas de situação de jogo. Percebe-se, assim, a necessidade de um bom trabalho de comunicação. Os voluntários do presente trabalho destacaram como necessidade sentida ou muito sentida a competência de descrever e implementar estratégias para aumentar a interação de comunicação entre os atletas. Essa competência pode estar em evidência devido às características coletivas da modalidade.

Planejar e implementar estratégias adaptadas ao desenvolvimento técnico e físico dos atletas no voleibol relacionou-se com o conhecimento do conteúdo. Destaca-se nessa área a competência de planejar a curto e a longo prazo, tendo em conta as necessidades dos atletas, os programas e as metas a atingir. Buchmann (s/d, cit. in Marcelo, 1992)(2) relata que o conhecimento aprofundado do conteúdo nos permite organizá-lo mentalmente, nos preparando para ensiná-lo.

Segundo Fernandes (1997)(14), não podemos entender avaliação como um processo que impeça 
o progresso dos alunos ou um entrave das oportunidades de aprendizagem. O ideal é constituir um meio privilegiado de promoção e de melhora da aprendizagem. No entanto, a avaliação foi uma área da formação percebida como necessária, mas com menor destaque dentre as restantes.

A Reflexão sobre sua prática pedagógica e a avaliação dos efeitos da sua ação, procurando oportunidades para seu desenvolvimento profissional, é outra área de formação percebida como necessária/muito necessária. Relacionou-se também com o planejamento e avaliação, proporcionando uma constante construção e reconstrução das situações e propostas, a fim de alcançar melhores resultados de desenvolvimento dos atletas e do grupo.

A Tecnologia foi outra área da formação percebida como necessária/muito necessária pelos inquiridos. Dentro do planejamento percebeu-se a utilização da tecnologia, ao criar planilhas para controle das sessões de treinamento, seu volume e intensidade. Dentro das avaliações percebeu-se o surgimento de novas tecnologias informáticas, permitindo a realização de testes, cada vez mais específicos e aplicáveis ao Voleibol.

Por fim, o Trabalho Colaborativo também foi uma área de formação percebida como necessária/muito necessária. Relacionar-se positivamente com colegas, pais e instituições ligadas ao voleibol, no apoio ao desenvolvimento dos atletas, para que estes tenham tranquilidade para a prática do esporte e, consequentemente, poderem alcançar suas metas individuais e coletivas. Gimeno Sacristán e Pérez Goméz (1998)(15) observam que o professor intervém num meio ecológico complexo, delimitado pela escola/clube/instituição e pela sala de aula/ginásio.

\section{CONCLUSÕES}

Os treinadores de Voleibol percebem necessidades de formação para sua atuação, mas nem a graduação em Educação Física, nem os cursos de nivelamento da CBV são capazes, por si só, de suprir essas necessidades, o que vem realçar o papel e a necessidade de um sistema de formação continuada ao longo da vida profissional.

Então, a fim de suprir tais necessidades, os treinadores buscam ações complementares de formação (seminários, palestras, oficinas, pós-graduações, estágios, acompanhamentos, entre outras). São preferidas pelos treinadores as ações de curto prazo de duração, de menor custo e de maior acessibilidade (como os cursos de nivelamento da CBV, as palestras e os seminários).

É possível entender que se deva ter o foco em programas de formação inicial e continuada que possibilitem o trabalho da troca de experiências com outros treinadores. As ações relacionadas com a troca de experiência com outros profissionais foram mais valorizadas do que aquelas voltadas a conteúdos apenas teóricos.

De acordo com os dados dos questionários e das entrevistas, foi possível perceber que a maioria dos treinadores buscou formação fora da especificidade do Voleibol, a fim de complementar e ampliar suas intervenções, principalmente, na iniciação e com jovens.

Os treinadores acreditam que o bom conhecimento das áreas de formação dentro do conteúdo Voleibol, pode ampliar sua capacidade de intervenção no treinamento. Logo, essas áreas de formação podem ser melhor trabalhadas na formação inicial, a fim de minimizar as lacunas encontradas pelos treinadores na sua atuação.

É importante ressaltar que as necessidades sentidas, muitas vezes foram comuns, independente do nível de atuação, não havendo diferença entre os treinadores que atuam na seleção brasileira e os treinadores que atuam na região Sudeste e Sul do Brasil.

\section{REFERÊNCIAS BIBLIOGRÁFICAS}

1- Durrwachter, G. Voleibol: treinar jogando. Rio de Janeiro: Ao Livro Técnico, 1984.

2- Marcelo, C. Como conocen los profesores la materia que enseñan. Algunas contribuciones de la investigación sobre conocimiento didáctico del contenido. In: Congresso 'Las didácticas específicas en la formación del profesorado', Santiago de Compostela, 6-10 julio, 1992.

3- Ramalho, BL. ; Nuñez, IB. Relatório Consultoria ao Centro Federal de Educação Tecnológica do RN (CEFET/RN). Mimeo. Natal, 2001.

4- Rodrigues, A. ; Esteves, M.. A análise das necessidades na formação de professores. Lisboa: Porto Editora, 1993. 
5- Kaufman, RA. Planificación de Sistemas Educativos. Ideas básicas concretas. México: Editorial Trillas, 1973.

6- Barbier, JM; Lesne, M. L'analyse des besoins en formation. Champigny-sur-Marne: R. Jauze, 1977.

7- Silva, MOE. A Análise de Necessidades de Formação na Formação Contínua de Professores: Um Caminho para a Integração Escolar. 2000. 286 f. Tese (Doutorado)- Faculdade de Educação, USP. São Paulo, 2000.

8- Stufflebeam, D. et al. Conducting Educational Needs Assessment. Boston: Kluwer-Nijhoff Publ, 1985.

9- Suarez, TM. Needs Assessment Studies. In T. Húsen; N. Postlethaite (Eds.), International Encyclopedia of Education. Oxford: Pergamon Pres, pp. 3496-3498. 1985.

10- Ferro, F. A percepção da importância da formação contínua como factor de desenvolvimento curricular na superação das necessidades de formação dos professores de Educação Física. 2005. 108 f. Dissertação de mestrado. Faculdade de Motricidade Humana, Universidade Técnica de Lisboa, 2005.

11- Triviños, A. Introdução à pesquisa em ciências sociais: A pesquisa qualitativa em educação. São Paulo: Atlas, 1987.

12- Bompa, T. Periodização: Teoria e metodologia do treinamento. São Paulo: Phorte Editora, 2002.
13- Novoa, A. O espaço público da Educação: imagens, narrativas e dilemas. In: AAVV, Espaços de Educação, tempos de formação. Lisboa. Fundação Calouste Gulbenkian, p.237 - 263, 2002.

14- Fernandes, D. Avaliação na Escola Básica Obrigatória: Fundamentos para uma Mudança de Práticas. In: Pedro da Cunha (org.), Educação em Debate, pp. 275294. Lisboa: Universidade Católica Portuguesa, 1997.

15- Gimeno Sacristán, J.; Pérez Gómez, A. Compreender e Transformar o Ensino. $4^{\mathrm{a}} \mathrm{ed}$. Porto Alegre: ArtMed, 1998.

\section{ENDEREÇO PARA CORRESPONDÊNCIA:}

Flávio Márcio Marinho, marinhofm@yahoo.com.br r. Monteiro Lobato, 187/602, b. Ouro Preto Belo Horizonte Minas Gerais. CEP- 31310-530

Prof. Esp. Alexandre Silva de Oliveira, alexandre138@yahoo.com.br.

Prof. Dr. Bruno Pena Couto, brunopena@yahoo.com.br Prof. Ms. Nádia Fernanda Schmitt Marinho, nfsmarinho@hotmail.com.

Profo Dr. Carlos Alberto Serrão dos Santos Januário, cjanuario@fmh.utl.pt. 